\title{
FY 2008 Miniature Spherical Retroreflectors - Final Report
}

\author{
NC Anheier \\ K Krishnaswami \\ BE Bernacki \\ CP Rodriguez \\ NA Klymyshyn
}

February 2009

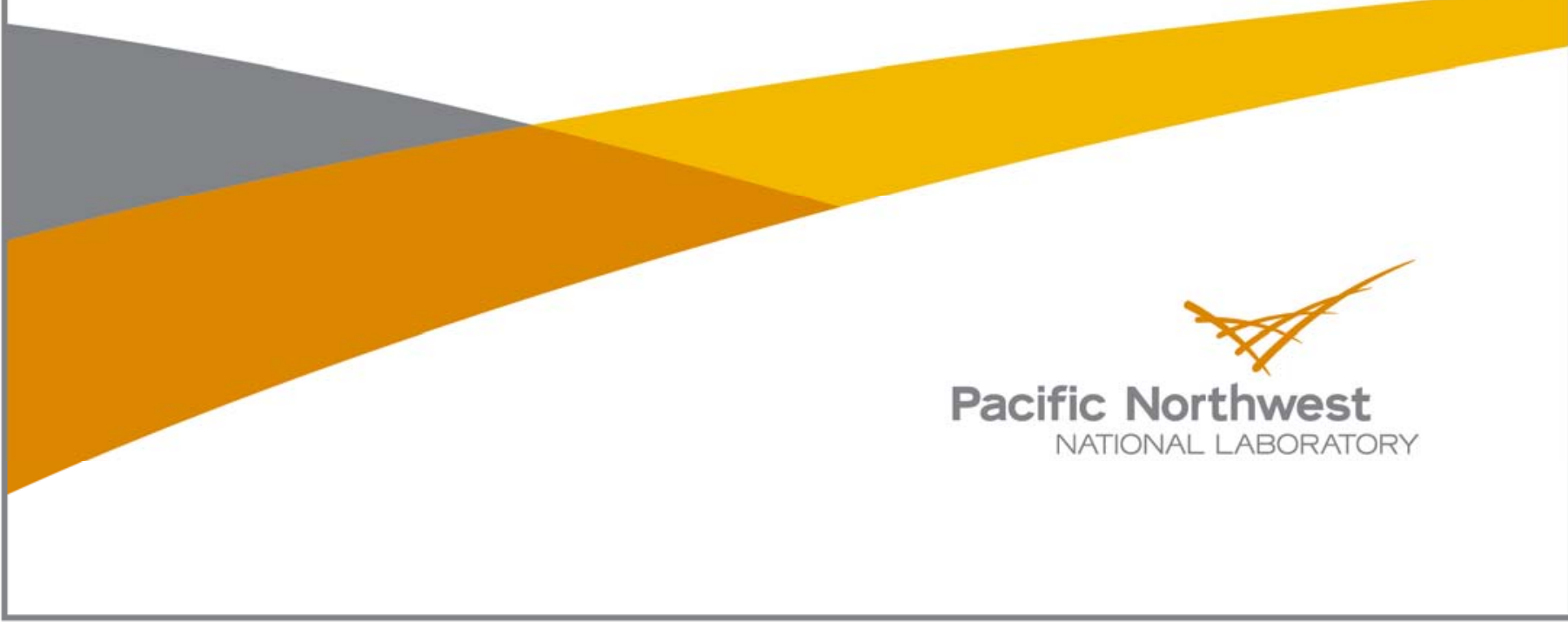




\title{
DISCLAIMER
}

This report was prepared as an account of work sponsored by an agency of the United States Government. Neither the United States Government nor any agency thereof, nor Battelle Memorial Institute, nor any of their employees, makes any warranty, express or implied, or assumes any legal liability or responsibility for the accuracy, completeness, or usefulness of any information, apparatus, product, or process disclosed, or represents that its use would not infringe privately owned rights. Reference herein to any specific commercial product, process, or service by trade name, trademark, manufacturer, or otherwise does not necessarily constitute or imply its endorsement, recommendation, or favoring by the United States Government or any agency thereof, or Battelle Memorial Institute. The views and opinions of authors expressed herein do not necessarily state or reflect those of the United States Government or any agency thereof.

\author{
PACIFIC NORTHWEST NATIONAL LABORATORY \\ operated by \\ BATTELLE \\ for the \\ UNITED STATES DEPARTMENT OF ENERGY \\ under Contract DE-AC05-76RL01830 \\ Printed in the United States of America \\ Available to DOE and DOE contractors from the \\ Office of Scientific and Technical Information, \\ P.O. Box 62, Oak Ridge, TN 37831-0062; \\ ph: (865) 576-8401 \\ fax: (865) 576-5728 \\ email: reports@adonis.osti.gov

\footnotetext{
Available to the public from the National Technical Information Service, U.S. Department of Commerce, 5285 Port Royal Rd., Springfield, VA 22161 ph: (800) 553-6847 fax: (703) 605-6900

email: orders@ntis.fedworld.gov

online ordering: http://www.ntis.gov/ordering.htm
}

This document was printed on recycled paper. 


\title{
FY 2008 Miniature Spherical Retroreflectors - Final Report
}

\author{
NC Anheier K Krishnaswami \\ BE Bernacki CP Rodriguez \\ NA Klymyshyn
}

February 2009

Prepared for

the U.S. Department of Energy

under Contract DE-AC05-76RL01830

Pacific Northwest National Laboratory

Richland, Washington 99352 



\section{Executive Summary}

Through the duration of the NNSA Office of Nuclear Nonproliferation Research and Development (NA-22) Miniature Spherical Retroreflectors lifecycle project, our research team focused on developing solutions to the fabrication bottleneck that has inhibited development and deployment of wide-angle optically interrogated chemical and radiological remote sensing technology. Our team advanced the concept of step-index clad retroreflectors to approximate an optimized, but yet unrealized spherical gradient index design. An intensive numerical simulation effort was undertaken that resulted in optimized step-index optical designs for mid-infrared applications. Geometric optics ray trace modeling was performed to better understand the geometrical dependencies of the miniature spherical retroreflector application. We adopted and advanced the concept of optical cross section, a metric that provides relative performance comparisons between different retroreflector designs. Our cross-section analysis demonstrated that our step-index design provided $90 \%$ of the range capacity of the ideal spherical index design.

Encouraged by the performance potential, our group investigated fabrication approaches for the stepindex design. Two potential methods were evaluated for step-index retroreflector fabrication. The first fabrication method was based on a Flow Focusing micro-nozzle. This processing begins by heating the glass in a platinum crucible and allowing it to flow through an orifice at the bottom of the crucible. The micro-nozzle injector is centered in the crucible orifice and pressurized with inert gas. A funnel-shaped lens of liquid is produced by the pressure drop across the orifice. By controlling the flow rate of liquid glass and the micro-nozzle pressure, a steady stream of small glass spheres can be produced. Integration of a second nozzle shell allows the simultaneous formation of a concentric shell, resulting in the desired step-index design. Our group investigated this approach by modifying the Pacific National Northwest Laboratory (PNNL) draw tower with a micro-nozzle assembly. Thermal visco-elastic properties of chalcogenide glass were studied and then the micro-nozzle process was evaluated. While the Flow Focusing micro-nozzle investigation demonstrated promising results and potential for mass production of miniature step-index retroreflectors, it became clear that the development costs were becoming prohibitive within the scope of the project budget, so we concentrated our efforts toward a compressionmolding approach.

During FY 2006 PNNL developed technical specifications for a custom compression molding press and worked with a commercial company to develop and deliver a press system specifically designed for our investigation. The remainder of the project focused on evaluating the molding behavior of candidate infrared glass materials and developing molding processes for the retroreflector elements. The thermal expansion mismatch between the core and cladding materials caused the clad retroreflectors to fracture upon cooling from molding to room temperature and was identified as a major challenge in both Super Vidron-BK7 and IG3-ZnS material systems. This is an unfortunate consequence of the clustering of physical properties of a moldable glass; namely, the low glass transition temperature that permits molding at reasonable temperatures along with a correspondingly high coefficient of thermal expansion. As a workaround, we proposed that room-temperature curable epoxies could be used to bond the shells to the ball core at the seams at room temperature, which would greatly restrict the temperature excursion the clad retroreflector would see. Although there would be an epoxy seam line that may distort the incoming beam slightly, the effects on retroreflector performance should be negligible. 
Research conducted in FY 2008 focused on developing additional solutions to the thermal expansion mismatch problem. We introduced a half-clad step-index design that has significant performance and fabrication advantages. The half-clad design offered to simplify the fabrication process, reduce stresses encountered in cooling, and consequently increase the yield of the molded retroreflector fabrication approach. While the omni-directional field of view has been reduced to $2 \pi$ steradians, the design offers the opportunity to reflectively coat the rear surface of the assembly and anti-reflection coat the first surface to obtain nearly $100 \%$ retroreflection return as compared with the theoretical $14.8 \%$ maximum return efficiency as described in a previous report. Even without surface coatings, the half-clad design exhibits cross-section performance falling between the homogeneous heavy metal oxide retroreflector with index of 2 and the optimized fully clad ZnS-IG3 retroreflector, making it an optically efficient solution for many deployment scenarios.

A simple, low-cost solution for mass production of infrared spherical retroreflectors remains elusive. PNNL identified the Flow Focused micro-nozzle early in the project as having the best potential for commercial production of miniature retroreflectors, yet prohibitively large investments were required to realize this approach. A less risky compress-molding approach was adopted, but conflicting material properties prevented decisive closure on the fabrication bottleneck. While the fabrication focus was not fully satisfied, PNNL made major contributions to this field by developing practical and efficient optical designs and the analysis formalism that clearly illustrates the relative performance and provides design rules and performance metrics to objectively compare competing designs. We anticipate this body of work will stimulate future research in this area and lead to enabling technology for remote sensing applications. 


\section{Acronyms and Abbreviations}

$\begin{array}{ll}\text { AOI } & \text { angle of incidence } \\ \text { AOR } & \text { angle of refraction } \\ \text { CS } & \text { cross section } \\ \text { CTE } & \text { coefficients of thermal expansion } \\ \text { CVD } & \text { chemical vapor disposition } \\ \text { FEA } & \text { finite element analysis } \\ \text { GLS } & \text { gallium lanthanum sulfide } \\ \text { HMOX } & \text { heavy metal oxide } \\ \text { IR } & \text { infrared } \\ \text { NA-22 } & \text { NNSA Office of Nuclear Nonproliferation Research and Development } \\ \text { PLC } & \text { programmable logic controller } \\ \text { PNNL } & \text { Pacific National Northwest Laboratory } \\ \text { RMS } & \text { root mean square } \\ \text { SR } & \text { Strehl Ratio } \\ T_{g} & \text { glass transition temperature } \\ \text { WFE } & \text { wavefront error }\end{array}$





\section{Contents}

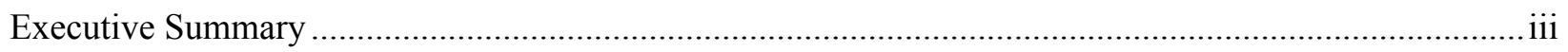

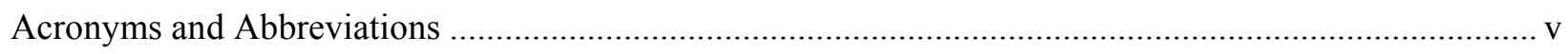

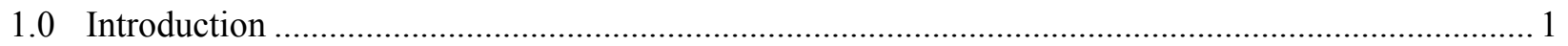

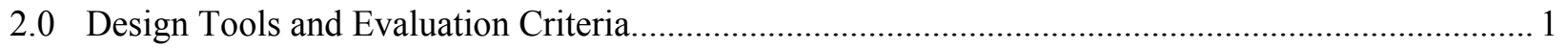

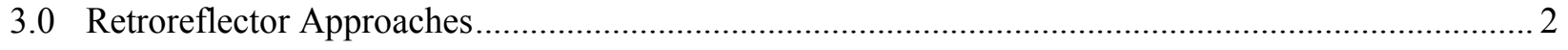

3.1 Homogeneous Spherical Retroreflector ......................................................................... 2

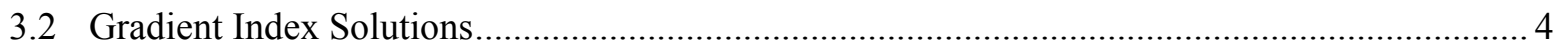

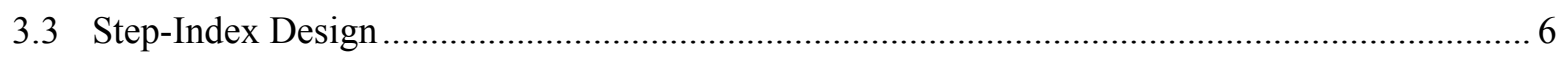

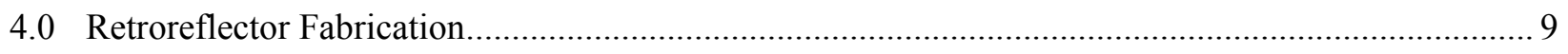

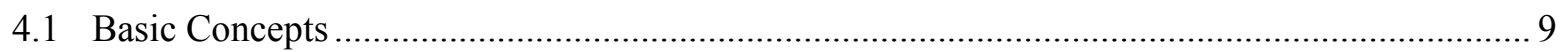

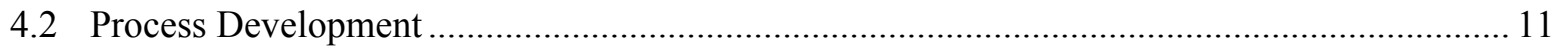

4.3 IR Miniature Retroreflector Fabrication........................................................................ 13

4.4 CTE Mismatch Issues and Potential Solutions...................................................................... 13

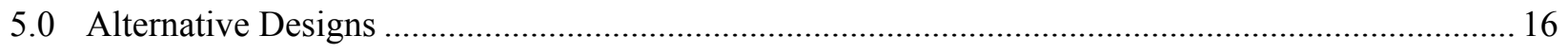

5.1 Spherical Half-Clad Miniature Retroreflector..................................................................... 16

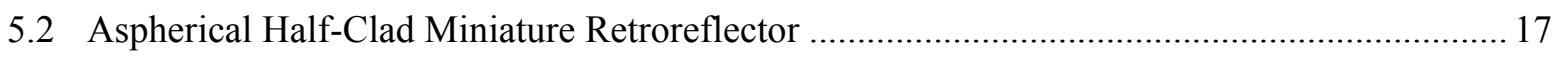

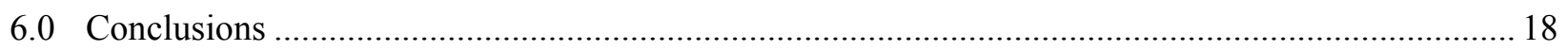

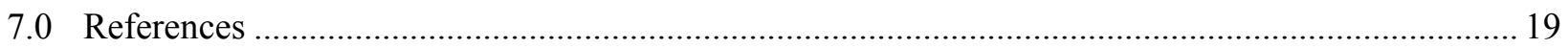




\section{Figures}

1. A Homogeneous Ball of Index $n$ Immersed in Air and Having Radius $R$ is Illuminated with a Ray of Light at Height $h$ above the Optical Axis........................................................................ 2

2. The Relationship Between Both Strehl Ratio and CS as a Function of Entrance Pupil Diameter for Simulations Performed at a Wavelength of $10 \mu \mathrm{m}$ 3

3. The Fraction of Light Returned from a Homogeneous Ball for Various Surface Reflectivity Values 4

4. The Index Profile and CS for a Gradient Index Design Having Spherical Symmetry that Uses a Starting Index Value Typical for IR Materials such as $\mathrm{As}_{2} \mathrm{Se}_{3} \ldots$

5. The Strehl Ratio Dependence as a Function of Entrance Pupil Diameter as the Clad Ball Design is Optimized, and the Dependence of Strehl Ratio on Entrance Pupil Diameter is Then Used to Compute the CS.

6. Comparison of the Step Index Profile and an Optimized Spherical Gradient Profile for a 7.744-mm-Diameter Sphere and the Optimized Step-Index Retroreflector with Incident and Reflected Ray Trajectories

7. The Retroreflected Beam Strehl Ratio Versus Input Beam Diameter for Three Different Retroreflector Designs

8. Cross Sections for the Four Designs' Strehl Ratios Shown Earlier in Figure 7 .............................. 8

9. Standoff Detection Range as a Function of Retroreflector Cross Section for the Four Designs' Shown in Figures 7 and 8

10. Sequential Steps Needed to Compression Mold the IG3 Cladding Around the ZnS Core to Form the Step-Index Retroreflector 10

11. Glass Molding Press Used to Produce the Miniature Spherical Retroreflectors

12. The Hemispherical Shells are Arranged Around the Core and Pressed to Yield the Final Assembly 12

13. A Partially Assembled Miniature Infrared Spherical Retroreflector with GLS Core as well as the Fully Assembled Retroreflector

14. FEA Modeling Results Showing the Peak Stress that Develops at the Boundary Between the ZnS Core and IG3 Shell After Cooling Following a Molding Sequence in the Fabrication of the Clad Ball Miniature Retroreflectors.

15. FEA Modeling Results for the Design in which GLS Glass is Substituted for the ZnS Core 15

16. Half-Clad Miniature Retroreflector Utilizing a ZnSe Core and IG3 Cladding..... 17

17. Strehl Ratio versus Input Beam Diameter for the Half-Clad Design

18. Strehl Ratio as a Function of Field Angle in the Case of an Aspherically Embossed HalfClad Miniature Retroreflector. 


\subsection{Introduction}

Optical retroreflectors find applications in fields as diverse as atmospheric research (Handerek et al. 2006), optical communications (Burmistrov et al. 2003), and optical metrology (Zürcher et al. 1995). Typically, they take the form of corner-cube reflectors or cat's eye reflectors. These configurations, however, are not isotropic and suffer from small acceptance angles that limit their effectiveness in some applications. Spherical retroreflectors are ideally isotropic and can be capable of extremely large acceptance angles, limited only by the effects of spherical aberration and available construction methods. Additionally, methods of low-cost production of spherical retroreflectors are becoming feasible using gradient index glass, glass compression molding, injection-molding technologies, and fluidized bed chemical vapor deposition (CVD). Because our application required the development of miniature retroreflectors with large acceptance angles and efficient returns for use in the mid- and long-wave infrared portion of the spectrum, we therefore focused our efforts on establishing efficient optical designs and practical fabrication methods based on spherical retroreflectors and glass compression molding.

\subsection{Design Tools and Evaluation Criteria}

Retroreflectors can be efficiently designed with commercially available computer-based lens design software, specialized in the optimization of imaging systems, by minimizing criteria such as spot size or wavefront error. For any retroreflector, the field of view, reflectance (loss at the initial air-glass interface and reflection from the final air-glass interface), and optical aberrations (mostly spherical) primarily limit the efficiency of the returned beam. One can achieve an acceptable design, though not optimal, by making use of the built-in optimization functions to achieve optimal imaging at the retroreflector rear surface for a given input beam size. Because retroreflectors are used in a double-pass configuration, the use of lens design optimization must account for the round trip through the device. Additionally, because the retroreflector return efficiency of the returned signal is of the greatest importance, usage of a scattering cross-section metric (or cross section), proposed by Oakley (2007) and adapted from radar terminology, is used as a figure of merit to develop potential retroreflector designs. The cross-section expression describing both a perfect retroreflecting mirror and a practical spherical retroreflector is given in Eq. (1).

$$
C S=\frac{\pi^{3}}{4 \cdot \lambda^{2}} d^{4} \Rightarrow \lim _{d \rightarrow D_{\max }} \frac{\pi^{3}}{4 \cdot \lambda^{2}} d^{4} S R(d) \quad\left[m^{2}\right]
$$

The first portion of the expression describes the cross section for a perfect circular mirror at normal incidence with diameter $d$. In the modified expression, we substitute $D_{\max }$ for $d$ in the limit. For a practical spherical retroreflector, $D_{\max }$ is the value of the aperture diameter at which the cross section (CS) reaches its maximum value. The Strehl Ratio (SR) of the returned beam is an optical figure of merit that compares the on-axis intensity of the point-spread function of the optical system to its ideal point-spread function, with a value of 0.8 generally accepted as the threshold for diffraction-limited performance 
(Welford 1986). The threshold for diffraction-limited performance in terms of root mean square (RMS) wavefront error (WFE) is $\lambda / 14$. Most lens design programs compute the RMS WFE from which SR is calculated using Eq. (2).

$$
S R \approx 1-\frac{4 \pi^{2}}{\lambda^{2}}(R M S W F E)^{2}
$$

The use of the CS as a figure of merit also helps one optimize the design for maximum return because it is not immediately apparent what criteria one should use to optimize the design. Should one demand diffraction-limited performance over a small aperture or relax performance over a larger input aperture to enjoy a greater return in optical flux from the retroreflector at the expense of increased wavefront error? It turns out that the CS metric reveals the latter approach is the most effective.

\subsection{Retroreflector Approaches}

\subsection{Homogeneous Spherical Retroreflector}

Initially, it is useful to consider the simplest solution and examine its limitations: the homogeneous spherical retroreflector or ball lens. Suppose we have a homogeneous ball of index $n$ and radius $R$, as shown in Figure 1, which is immersed in air. A ray of light from infinity strikes the ball at an initial angle of incidence (AOI), with respect to the surface normal at height $h$ above the optical axis where it is refracted at some angle of refraction (AOR), also with respect to the surface normal, according to Snell's Law. If we write an expression for perfect imaging of the impinging light at the intersection of the optical axis and rear surface of the sphere, we can develop a relationship between the index of refraction $n$, the radius of curvature $R$, and the incoming ray height $h$ while eliminating terms for the angles of incidence and refraction. The expression for the index of refraction required for perfect imaging as a function of ray height $h$ and sphere radius $R$ is given in Eq. (3).

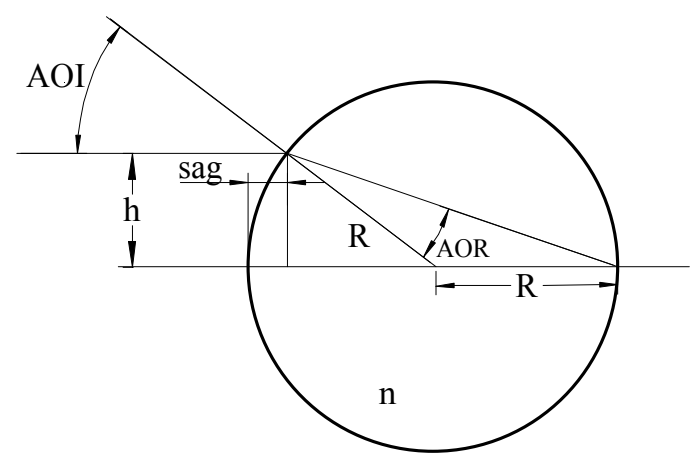

Figure 1. A Homogeneous Ball of Index $n$ Immersed in Air and Having Radius $R$ is Illuminated with a Ray of Light at Height $h$ above the Optical Axis. The ray strikes the ball with initial AOI and is refracted with an AOR according to Snell's Law. 


$$
n=\sqrt{2\left(1+\sqrt{1-\left(\frac{h}{R}\right)^{2}}\right)}
$$

Two extreme limits are of interest to us here: the paraxial regime and the case of a marginal ray that strikes the periphery of the sphere. In the paraxial regime, very near the optical axis, $h \rightarrow 0$ as $n \rightarrow 2$, while in the case of a marginal ray $h \rightarrow R$ as $n \rightarrow \sqrt{ } 2$. Because our sphere is homogeneous, we must select one single optimum index of refraction to maximize the return from the retroreflector. We are forced to choose an index of 2 for the homogeneous ball because it provides good image quality (and hence efficient retroreflection) in the paraxial regime. Furthermore, optical materials exist that meet these requirements in the visible and infrared portions of the spectrum; for example, S-LAH79 ${ }^{(a)}$ and $\mathrm{AgCl}$ and newly identified heavy metal oxide glasses (HMOX), respectively.

We can now apply the CS figure of merit on a homogeneous ball to determine its cross section. For this example, we assume a 5-mm-diameter sphere of $\mathrm{AgCl}$ and an incident beam at a wavelength of $10 \mu \mathrm{m}$. For the work presented in this report, sequential ray tracing results were performed using Zemax lens design software. ${ }^{(b)}$ To estimate CS, we construct a model of the homogeneous ball lens in reflection and calculate SR as a function of entrance pupil diameter. The output of this calculation is then used to determine the CS using Eq. (1) as a function of wavelength, entrance pupil diameter, and SR. Plots showing SR and CS as a function of the entrance pupil diameter are shown in Figure 2. Note that the optimum entrance pupil diameter required to maximize the CS is 2.31 resulting in a SR of 0.68 , which is below the diffraction limit of 0.8 . These results show the interplay between the design tradeoffs of opening up the aperture to deliver greater optical flux in reflection and the dependence of the SR on entrance pupil diameter. The end result is enhanced retroreflector performance obtained using the CS metric versus a simple minimum spot size or wavefront quality approach.
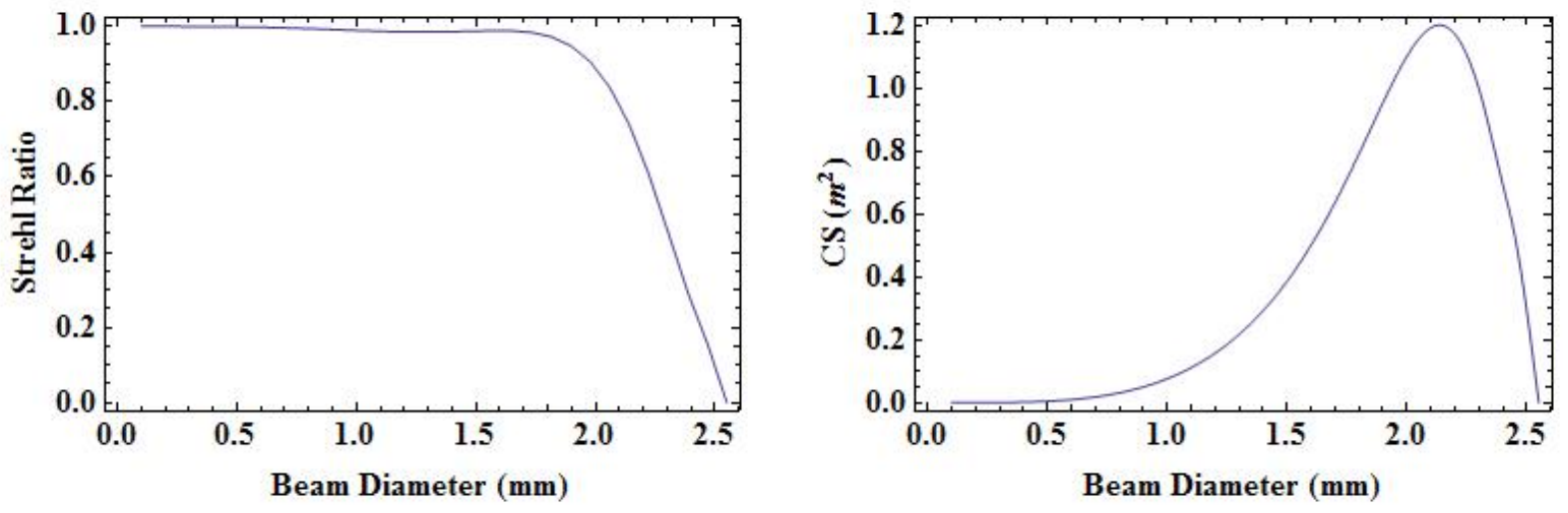

Figure 2. The Relationship Between Both Strehl Ratio (left) and CS (right) as a Function of Entrance Pupil Diameter for Simulations Performed at a Wavelength of $10 \mu \mathrm{m}$. The optimum entrance pupil diameter for the 5-mm-diameter $\mathrm{AgCl}$ ball is $2.31 \mathrm{~mm}$, which results in a double-pass Strehl Ratio of 0.68 .

(a) http://www.oharacorp.com/pdf/eslah79.pdf

(b) http://www.zemax.com 


\subsection{Gradient Index Solutions}

The ideal optical spherical retroreflector is the Luneburg lens (Born and Wolf 1986), which is an inhomogeneous sphere that brings a collimated beam of light to a perfect focus at the rear surface of the sphere. Its gradient index function is spherically symmetric and is a function of the sphere radial coordinate $r$. For a sphere of unit radius with the origin at the center, the gradient index function can be written as shown in Eq. (4).

$$
n(r)=\sqrt{2-r^{2}}(0 \leq r \leq 1)
$$

Two problems are evident with this theoretical structure. First, for a sphere in air, the index of refraction at the surface of the sphere must equal that of the immersion medium, with $n=1$, which is not practically realizable. Second, while neither reflection nor optical loss would occur at the incident surface of the lens, neither would reflection occur at the rear surface because there would be no index of refraction contrast between the sphere and immersion medium. For a homogeneous sphere in air, the fraction of the incident light retroreflected for an input ray at normal incidence to the surface of the sphere is given by Eq. (5). This expression takes into account reflective losses from the first surface and reflection from the second surface. Here the variable $r$ denotes reflectivity of the sphere surface.

$$
\text { return }=r(1-r)^{2} \Rightarrow r=\left(\frac{n-1}{n+1}\right)^{2}
$$

If we plot the return fraction of light from the sphere as a function of surface reflectivity, as shown in Figure 3, we find that the optimum return for a homogeneous sphere occurs when the reflectivity of the surface is 0.33 and results in a maximum return of $14.8 \%$. Therefore, for most glasses, some kind of partially reflecting thin-film coating will be required to maximize the return from an isotropic spherical retroreflector.

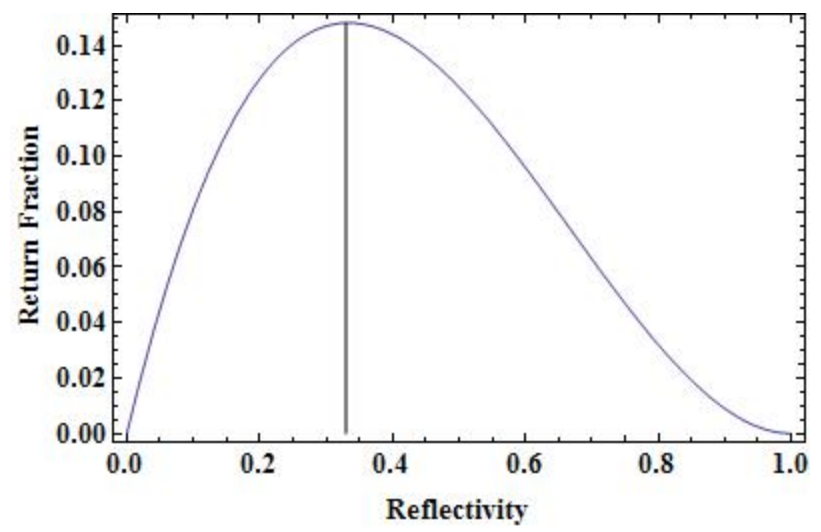

Figure 3. The Fraction of Light Returned from a Homogeneous Ball for Various Surface Reflectivity Values. The optimum return efficiency occurs for a reflectivity of 0.33 . 
In practice, a physically realizable solution will have to start with an optical glass with $n>1.3$ at the surface. In the mid- and long-wave infrared (IR) region, from $3 \mu \mathrm{m}$ to $12 \mu \mathrm{m}$, many common IR optical materials have $n>2$. As a design example, consider a gradient index spherical retroreflector design that assumes a starting index equal to that of a chalcogenide infrared glass. We choose $\mathrm{As}_{2} \mathrm{Se}_{3}$, with an index of refraction of 2.78 at $10 \mu \mathrm{m}$ and a sphere diameter of $5 \mathrm{~mm}$ as the design starting point. The "best" gradient index profile that minimizes the wavefront error function in reflection will differ depending on the diameter of the beam used for optimization. Therefore, the best design to maximize CS was found by varying the diameter of the input beam (or entrance pupil diameter) and calculating SR for each choice of beam diameter as the gradient index parameters were optimized. The SR versus diameter data was then used to compute CS and determine the optimum beam size to use to maximize CS. The parabolic spherical gradient index model used to describe the profile is given in Eq. (6).

$$
\begin{aligned}
& n=n_{0}+\alpha(r-R)+\beta(r-R)^{2}, \text { where } \\
& r=\frac{R}{|R|} \sqrt{x^{2}+y^{2}+(R-z)^{2}}
\end{aligned}
$$

In Eq. (6) the isoindex profiles are centered about the point $z=R$, where $R$ is the radius of the sphere. The starting index $n_{0}$ is measured at the vertex of the sphere where $z=0$ and not at its center as defined earlier for the Luneburg lens. In this example, it was found that the optimum input beam diameter required to maximize CS is $2.92 \mathrm{~mm}$ for a $5-\mathrm{mm}$-diameter sphere, which results in a SR of 0.66 after retroreflecting from the sphere. Plots showing the resulting index profile and CS versus input beam diameter are shown in Figure 4. The necessary change in index required to achieve this design is 0.53 , which is larger than index changes achievable using any known method of producing gradient index materials, especially in the infrared. Gradient index solutions have been proposed and demonstrated in the visible (Kikuchi et al. 1981; Koike et al. 1989), near-infrared (Handerek et al. 2005), and infrared (Pickering et al. 1986) but with more modest $\Delta \mathrm{n}$ values of 0.015 for polymer approaches in the visible and potentially 0.16 for a chemical vapor deposition method with infrared materials based on a ball geometry having a $2.5-\mathrm{mm}$ radius.
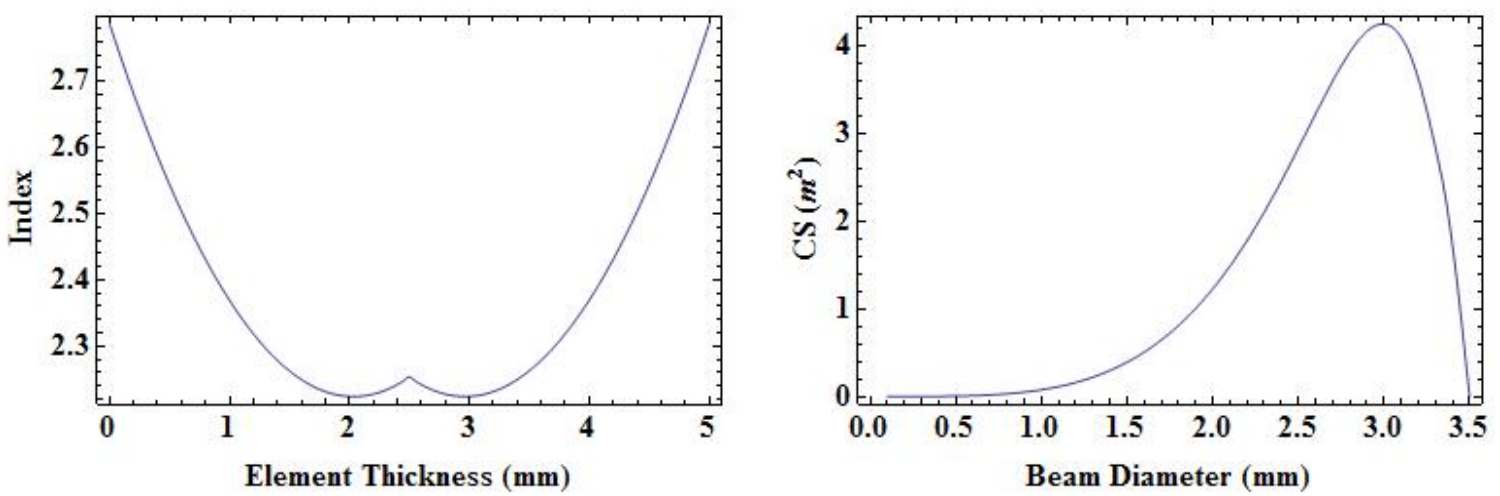

Figure 4. The Index Profile (left) and CS (right) for a Gradient Index Design Having Spherical Symmetry that Uses a Starting Index Value Typical for IR Materials such as $\mathrm{As}_{2} \mathrm{Se}_{3}$ 


\subsection{Step-Index Design}

To approximate the ideal gradient index profile, shown in Figure 4, a solution for an efficient retroreflector in the infrared was proposed using a step-index or clad ball structure. Figure 4 revealed that for a starting index of 2.78 at the surface, we must reach a value of approximately 2.24 at the core. In general, the index will tend towards a value of 2 at the center. The shape of the index profile will be concave if the starting index at the edge of sphere is greater than 2 and convex if the starting index is less than 2. We can construct a step-index approximation to this continuous profile using a commercial chalcogenide glass for the outer shell of a two-layer structure, for instance $\mathrm{Ge}_{30} \mathrm{As}_{13} \mathrm{Se}_{32} \mathrm{Te}_{25}$ (IG3) glass ${ }^{(\mathrm{c})}$ as the cladding and $\mathrm{ZnS}$ as the core with the clad and core having refractive indices of 2.787 and 2.200, respectively, measured at $10 \mu \mathrm{m}$. We arbitrarily chose a core diameter of $5 \mathrm{~mm}$ because this size is readily commercially available for device prototyping. The design was optimized for maximum CS by varying the thickness of the cladding while minimizing the wavefront error merit function. The optimum CS was achieved when the design was optimized for an input beam diameter of $3.97 \mathrm{~mm}$. The final design culminated in a 1.372-mm-thick IG3 cladding surrounding a 5-mm ZnS core, which resulted in a total retroreflector diameter of $7.744 \mathrm{~mm}$. Plots showing the variation in Strehl Ratio and CS as a function of entrance pupil or input beam diameter are shown in Figure 5. A plot showing an ideal spherical gradient index profile with a superimposed step-index profile, as well as a plot showing the step-index retroreflector design with ray trajectories at a pupil diameter of $3.97 \mathrm{~mm}$, is given in Figure 6. Note that because IG3 has an index of refraction of 2.787 at $10 \mu \mathrm{m}$, and surface reflectance of $22.3 \%$, the reflectance from the clad ball design taking into account front and rear surface reflections is approximately $13.4 \%$, or very nearly the optimum value of $14.8 \%$ shown earlier to be the theoretical maximum return for an optimally coated spherical retroreflector.
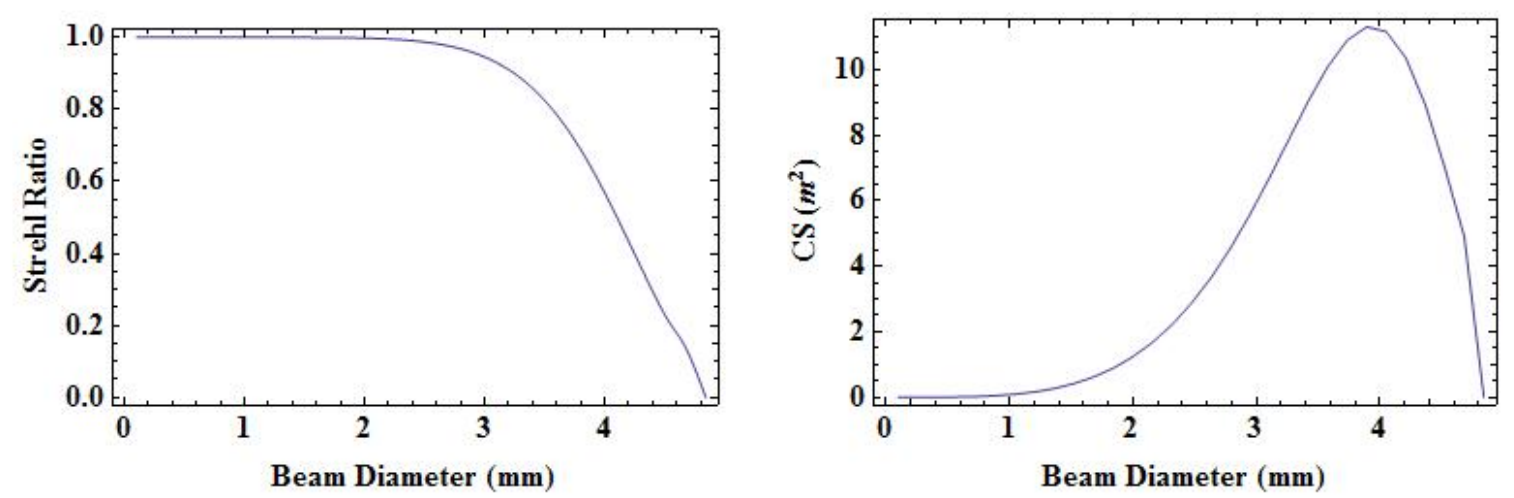

Figure 5. The Strehl Ratio Dependence as a Function of Entrance Pupil Diameter as the Clad Ball Design is Optimized (left), and the Dependence of Strehl Ratio on Entrance Pupil Diameter is Then Used to Compute the CS (right) that reveals that the peak CS is achieved for an Entrance Pupil Diameter of $\sim 4 \mathrm{~mm}$. When the design is optimized for a beam diameter of $4 \mathrm{~mm}$, a Strehl Ratio of 0.61 results for the double-pass beam.

(c) http://www.vitron.de 

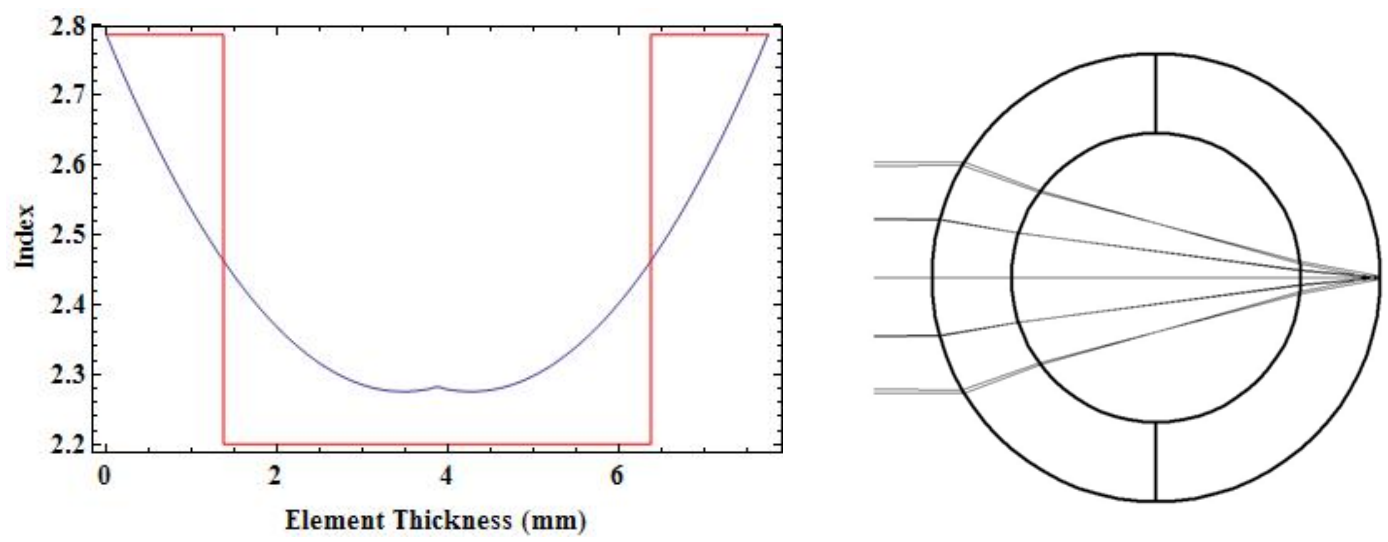

Figure 6. Comparison of the Step Index Profile and an Optimized Spherical Gradient Profile for a 7.744-mm-Diameter Sphere (left) and the Optimized Step-Index Retroreflector with Incident and Reflected Ray Trajectories (right)

Finally, it can be shown that the performance of a step-index clad ball design is nearly the same as that of the spherically symmetric gradient index solution over comparable input apertures and equal retroreflector diameters. The retroreflected beam SR as a function of increasing input beam diameter is shown in Figure 7 for three comparison designs: homogeneous $\mathrm{ZnS}$ and HMOX spheres, step-index sphere with IG3 cladding and $\mathrm{ZnS}$ core, and a spherical gradient index design. Because CS is proportional to SR, one can see that the clad sphere predicts nearly the same performance as the superior, but physically unrealizable, gradient index solution. The relative CS performance is shown in Figure 8.

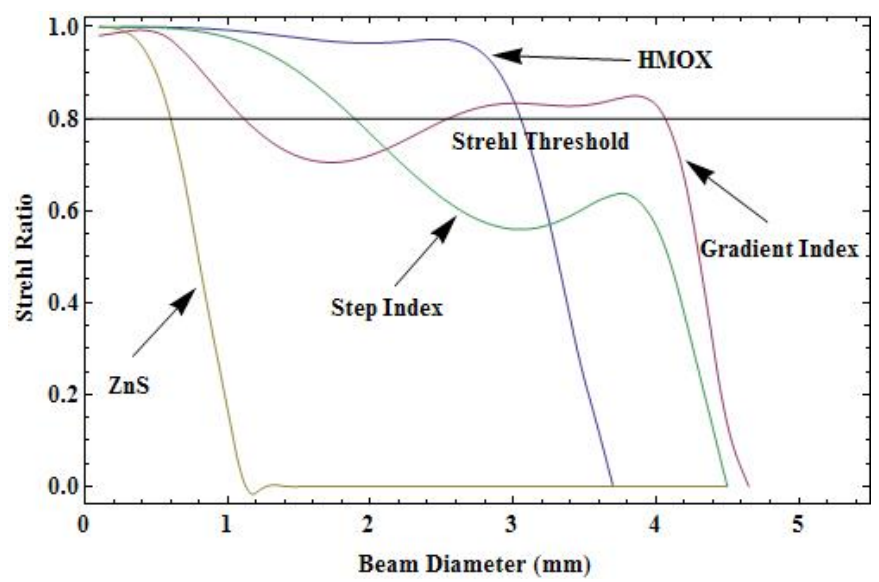

Figure 7. The Retroreflected Beam Strehl Ratio Versus Input Beam Diameter for Three Different Retroreflector Designs: homogeneous ball ( $\mathrm{ZnS}$ and HMOX glasses), clad or step-index sphere, and gradient index variants. Note that the clad sphere provides nearly the same performance as the ideal (and physically unrealizable) gradient index sphere. Also, the $\mathrm{n} \approx 2$ HMOX glass provides good performance over a wide aperture range. 


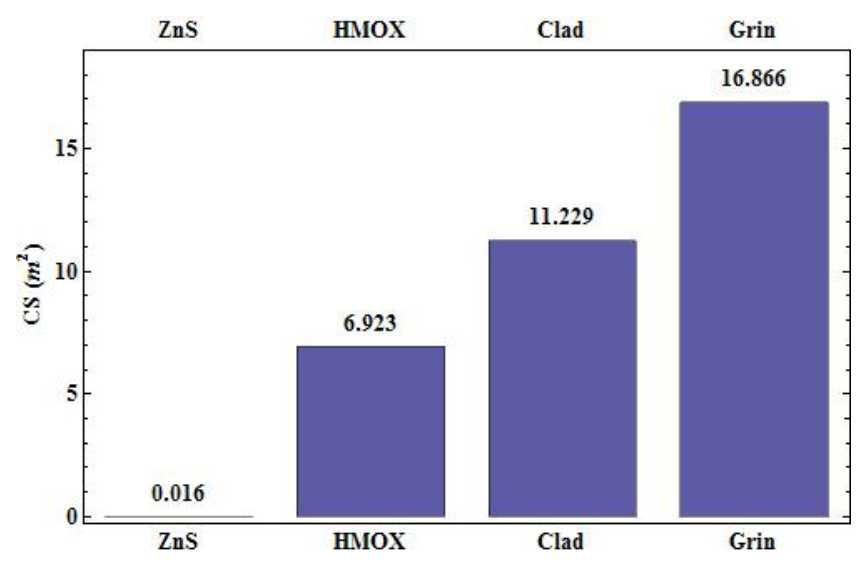

Figure 8. Cross Sections for the Four Designs' Strehl Ratios Shown Earlier in Figure 7. The HMOX homogeneous ball with index of $\mathrm{n}=2$ provides reasonable return performance, but it displays only about half the CS of the clad ball design.

The calculated CS can now be used to determine the normalized standoff detection range potential for each retroreflector design, because the range varies as the fourth root of the CS, Range $\propto \sigma^{1 / 4}$. The standoff detection range as a function of CS is shown in Figure 9. The results of this analysis are significant. Even though the CS of the step-index design is reduced by 33\% compared to the spherical gradient index design, the standoff range potential is reduce by only $10 \%$. In addition, the HMOX design now looks promising, because the $58 \% \mathrm{CS}$ reduction leads to only a $20 \%$ standoff range reduction. This analysis demonstrates the importance of using the proper design rules and performance metrics to objectively compare competing designs. This also leads to the conclusion that an overly constrained and optimized optical design (the spherical-index design in this case) provides only modest performance gains compared to our step-index approximation. Furthermore, the newly identified HMOX glass could be a first choice for spherical retroreflector designs, because it features single index construction, mid-infrared transparency, and impressive standoff range performance for its simplicity. 


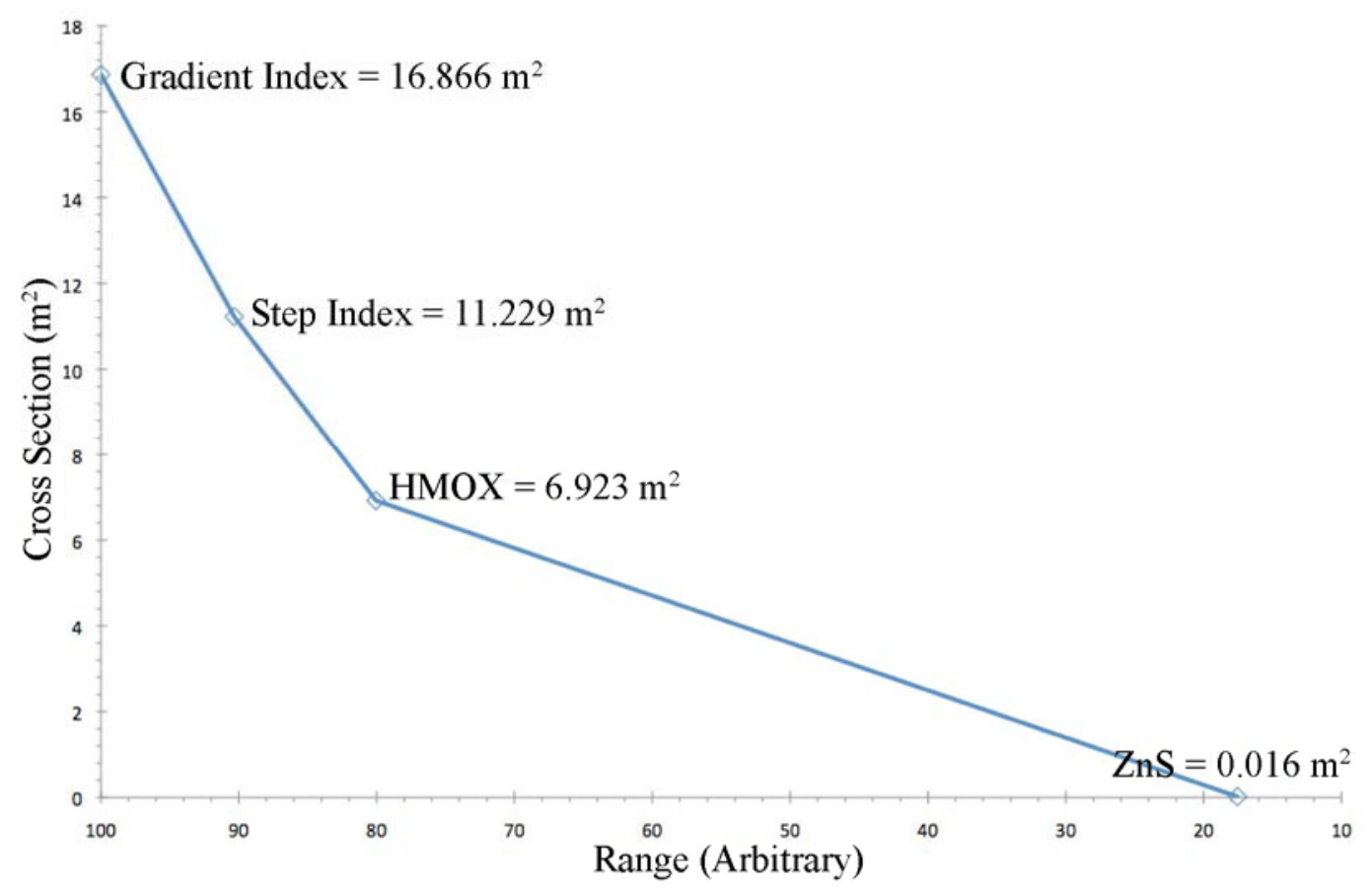

Figure 9. Standoff Detection Range as a Function of Retroreflector Cross Section for the Four Designs' Shown in Figures 7 and 8. The cross-section analysis shows that the step-index design provides $90 \%$ of the range capacity of the ideal spherical index design.

\subsection{Retroreflector Fabrication}

\subsection{Basic Concepts}

It was shown in the previous section that the step-index clad sphere design can approach the performance of a spherically symmetric gradient index retroreflector. We fabricated step-index clad spheres using glass compression molding of a chalcogenide glass shell over a $\mathrm{ZnS}$ core. IG3 has a glass transition temperature $\left(\mathrm{T}_{\mathrm{g}}\right)$ of $275^{\circ} \mathrm{C}$, which is far below the $1827^{\circ} \mathrm{C}$ melting point of $\mathrm{ZnS}$, ensuring that the molding process will not distort the core material. The molding process consists primarily of two steps: forming the shell halves for the cladding and then pressing the final assembly around the spherical core. The steps are shown schematically in Figure 10. 


\section{Step 1}

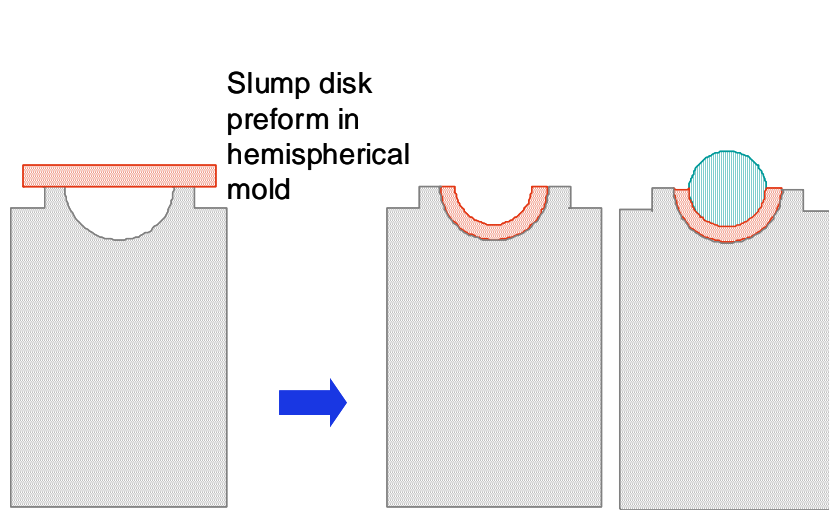

Step 2

Load

core and

press

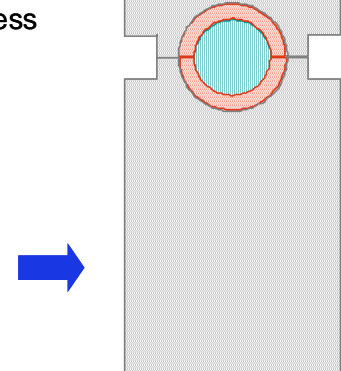

Figure 10. Sequential Steps Needed to Compression Mold the IG3 Cladding Around the ZnS Core to Form the Step-Index Retroreflector

Glass compression molding is typically used in large volume lens manufacturing required for consumer goods or to fabricate small or complex optical elements in glass that are otherwise difficult to fabricate using more traditional methods (Maschmeyer et al. 1983). Either metal or ceramic molds are used depending on production volume, glass transition temperature, and features required in the optic. The molds can be fabricated either by single-point diamond turning (metal molds) or deterministic precision grinding (ceramics). Because the thermal properties of chalcogenide glasses are similar to low$\mathrm{T}_{\mathrm{g}}$ glasses used for molding visible optics, these processes can easily be adapted to molding infrared chalcogenide optics (Zhang et al. 2003). In our project, we obtained a research-grade glass molding press, ${ }^{(d)}$ shown in Figure 11, which enabled us to fabricate the hemispherical shells and perform the final retroreflector assembly pressing operation. The press has an enclosed chamber that can be evacuated and back filled with an inert gas to avoid oxidation effects at the elevated process temperature of $\sim 330^{\circ} \mathrm{C}$. It uses a programmable logic controller (PLC) to control press parameters such as time, upper and lower mold temperatures, ram position, cooling, and pressing force.

(d) http://www.dit-fla.com 


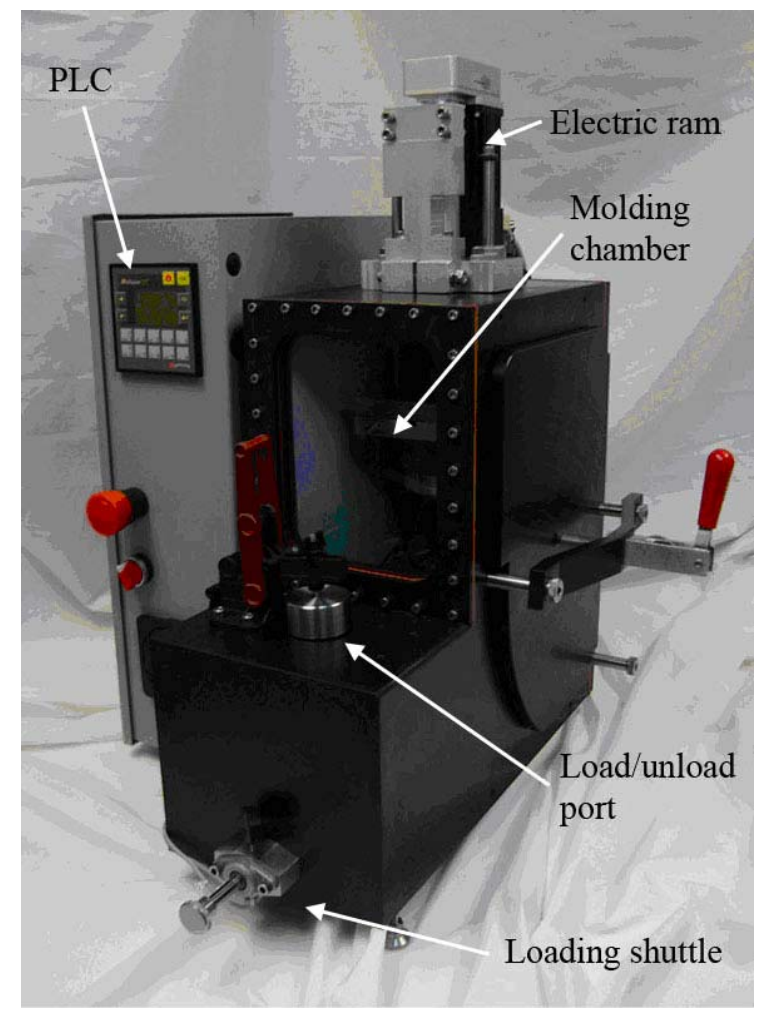

Figure 11. Glass Molding Press Used to Produce the Miniature Spherical Retroreflectors. Pressing takes place in an inert atmosphere within the molding chamber under prescribed temperature, time, and mold position parameters.

\subsection{Process Development}

To develop initial molding process methods for the chalcogenide-clad infrared miniature retroreflectors, a low-cost moldable glass was identified as an ideal candidate because of similarities in its thermal properties with the targeted IG3 cladding. K-PG325 Super Vidron glass from Sumita Glass Company ${ }^{(\mathrm{e})}$ has a $\mathrm{T}_{\mathrm{g}}$ of $285^{\circ} \mathrm{C}$ that is very close to the $275^{\circ} \mathrm{C}$ value for IG3. Super Vidron is markedly less expensive than IG3 and does not generate a potentially hazardous waste stream, making it an ideal candidate for initial process development.

Super Vidron is only available as polished spherical preforms from the manufacturer. These performs were specified to have the same volume as the design value of the shell for the IG3-clad retroreflector. Forming the hemispherical shell was a two-step process when starting with a sphere. First, the spheres were pressed into solid hemispheres by using a combination of flat and concave molds. Replacing the flat with a convex mold for the second step, the solid hemispheres were subsequently pressed to form hemispherical shells. The fabricated hemispherical shells were then used to clad a high- $\mathrm{T}_{\mathrm{g}}$ glass core in a third compression-molding step that used two concave molds.

(e) http://www.sumita-opt.co.jp/en/optical/optical04.htm 
Once the process for hemispherical shell production was established, the shells and core in the prototype retroreflector could be assembled. For cost and waste-related reasons, we chose BK7 glass as the core for process development as its $\mathrm{T}_{\mathrm{g}}$ is similar to that of $\mathrm{ZnS}$. Additionally, the coefficients of thermal expansion (CTE) for BK7 and $\mathrm{ZnS}$ are also well-matched for process development reasons: $7.1 \mathrm{ppm} / \mathrm{K}$ for BK7 versus $6.7 \mathrm{ppm} / \mathrm{K}$ for $\mathrm{ZnS}$ (Klocek 1991). It is important to note that this device was fabricated purely for purposes of process development and had no optical function; that is, the core and cladding materials were not optimum choices for retroreflector applications in the visible. They were simply chosen for their physical properties as surrogates while developing our pressing methods.

To assemble the finished clad spherical retroreflector, one hemispherical shell and the core are placed in the press centered in a concave spherical mold in the lower mold assembly. A matching spherical mold is mounted in the upper mold assembly. A pressing profile was established that defines: (1) amount of time the assembly (molds + glass) soaks at pressing temperature before both molds come in contact with the glass, (2) the ram position to move the molds once press temperature has reached, (3) the amount of time to hold at the pressing position to make sure that the glass has flowed completely, and (4) the cooldown temperature profile.

Cladding is a two-step process in which the first ball and shell assembly is lightly pressed to allow the shell to flow slightly and adhere to the core. To finish the assembly, a new shell is placed into the bottom mold, and the previously formed shell and core are aligned on top of the shell (Figure 12). As was explained earlier, the PLC controls the time, temperature, and ram position profiles to press the two shells around the core until they meet at the seam line and excess glass is forced between the two mold halves. This seam or parting line should be removable by post-polishing the parts after completion of the molding process. Ideally, the cladding design will be slightly thicker than called for in the optical design to allow for material removal in the final polishing step.
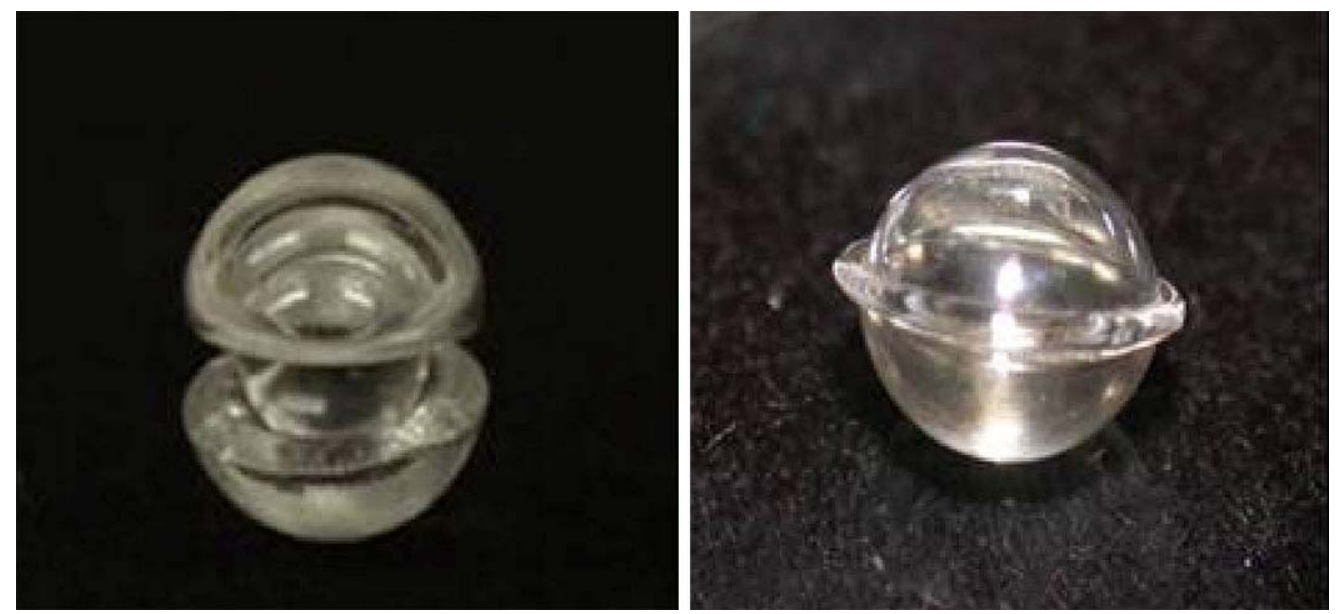

Figure 12. The Hemispherical Shells are Arranged Around the Core (left) and Pressed to Yield the Final Assembly (right) 


\subsection{IR Miniature Retroreflector Fabrication}

Once the initial process development steps yielded acceptable examples of clad balls, our work shifted to infrared materials to determine if there were any issues not uncovered by working with Super Vidron and the BK7 core. One significant difference in the transition to infrared materials is the preform shape used to form the shells. IG3 is procured in polished disk form with appropriate thickness and diameter chosen to ensure the correct shell volume. Prior work with spherical preforms capitalized on the self-centering nature of the spherical preform within the concave mold surface. The new disk preform places a greater demand on the manual process of centering the preform within the concave mold. With this one distinction, the fabrication steps were replicated as previously described in the process development section with the exception that the windows were pressed into shells in a single step using the combination of convex and concave molds. Initial prototypes were fabricated using both $\mathrm{ZnS}$ and gallium lanthanum sulfide ${ }^{(\mathrm{f})}$ (GLS) glass balls. GLS is a chalcogenide glass that is an attractive alternative to $\mathrm{ZnS}$ as the core material. GLS possesses a higher CTE compared to $\mathrm{ZnS}(10 \mathrm{ppm} / \mathrm{K})$ that is better matched to the IG3 cladding glass, which has a CTE of $13.4 \mathrm{ppm} / \mathrm{K}$. Good matching of CTEs is essential to ensuring the mechanical integrity of the retroreflector as the device cools from pressing temperature to room temperature. The partially assembled and fully molded spherical retroreflector are shown in Figure 13 as an example of our initial efforts.
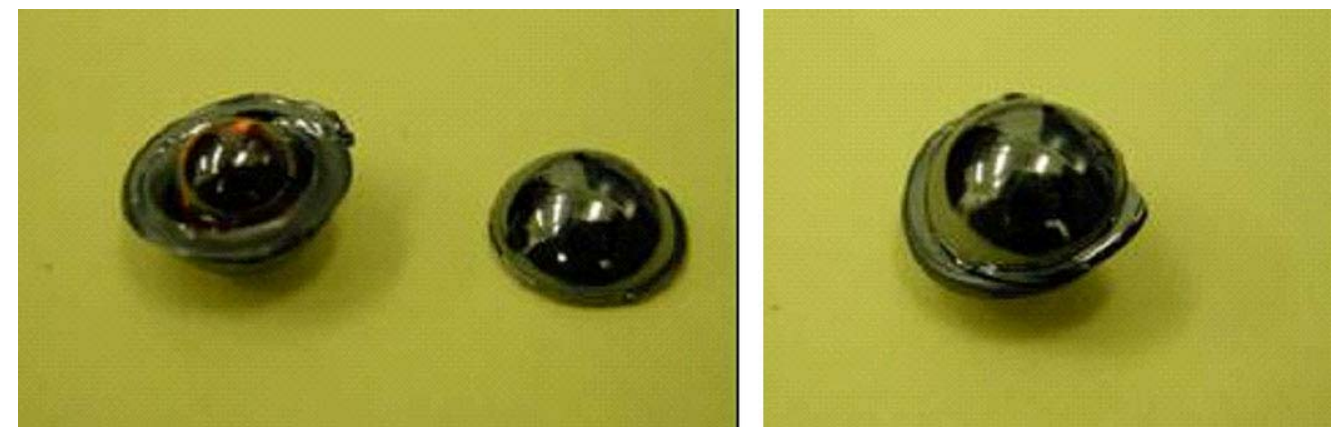

Figure 13. A Partially Assembled Miniature Infrared Spherical Retroreflector (left) with GLS Core as well as the Fully Assembled Retroreflector (right). Note the asymmetrically shaped excess glass at the seam line. This asymmetric feature is a consequence of a poorly centered preform prior to shaping the hemispherical shell. This artifact will likely be of little consequence because the seam line can be removed during post polishing.

\subsection{CTE Mismatch Issues and Potential Solutions}

A basic clad retroreflector fabrication approach, using molded cladding layers over a spherical glass core, was presented in this report. This approach proves to be a viable method of fabricating spherical retroreflectors that promise performance nearly comparable to a gradient index retroreflector in the midand long-wave IR region. One of the most challenging issues encountered during process development was molding the higher-CTE cladding over a lower-CTE core. Essentially, at press temperature of

(f) http://www.chgsouthampton.com/ 
$\sim 330^{\circ} \mathrm{C}$, the dimensions of the cladding shell increases substantially compared to those of the core. Because the mold surfaces are fixed and the glass is incompressible (at press temperature), the cladding is therefore in intimate contact with the core, and the clad ball conforms to the dimensions of the mold at its outer diameter. However, as the molded retroreflector cools, the cladding shrinks more than the core. The shrinkage of the cladding puts it in tension and causes either delamination or total mechanical failure of the cladding layer. To illustrate this effect, we can show how the core made of $\mathrm{ZnS}$, with $\alpha_{\mathrm{ZnS}}$ defined as its CTE, grows from its original radius $\left(r_{0}\right)$ due to a change in temperature $(\Delta T)$. As the temperature of $\mathrm{ZnS}$ rises from ambient $\left(30^{\circ} \mathrm{C}\right)$ to press temperature $\left(330^{\circ} \mathrm{C}\right)$ then, using the linear expression below, we can determine that the radius of the ball at press temperature with an initial diameter of $5 \mathrm{~mm}$ increases by $5.0 \mu \mathrm{m}$.

$$
\Delta r=r_{0} \alpha_{Z n S} \Delta T=2500 \mu m \cdot \frac{6.7 \times 10^{-6}}{{ }^{\circ} C}(330-30)^{\circ} C=5.0 \mu m
$$

Because the inner radius of the IG3 cladding is in contact with the core and the outer radius is constrained by the mold, the inner radius of the cladding also grows by $5.0 \mu \mathrm{m}$. At room temperature, the core shrinks back to a 5.0-mm diameter. Because the CTE of the cladding is approximately twice that of the core, the inner radius of the cladding attempts to shrink by $\sim 10.1 \mu \mathrm{m}$ at which point shear and tensional forces typically cause the shell to delaminate or shatter.

To obtain a clearer picture of the stresses involved with the molding process during cooling, a finite element analysis (FEA) modeling effort was undertaken to model the stresses seen as the clad-ball assembly cools. The Ansys ${ }^{(\mathrm{g})}$ FEA package was used to model the solid model created in SolidWorks ${ }^{(\mathrm{h})}$, a three-dimensional parametric modeling program. The IG3-ZnS system develops peak stresses that approach $6 \mathrm{kpsi}$. A rule of thumb for tensile design strengths of most glass materials is typically 1-1.5 kpsi (Doyle and Kahan 2003). Clearly, the material system required for the clad optical design exceeds this limit. Additionally, due to the stress induced in the molding process and inherently brittle nature of chalcogenide glasses when compared to oxide and fluoride optical glasses, the failure threshold is likely lower than the above figure. The output of the FEA model is shown in Figure 14, which shows the peak stress along the seam line between the $\mathrm{ZnS}$ core and IG3 shell.

An alternate solution for the core material has been considered that uses the GLS chalcogenide glass, which has a CTE of $10 \mathrm{ppm} / \mathrm{K}$. This is about 1.5 times greater than $\mathrm{ZnS}$ and so the CTE mismatch at room temperature is reduced, which was thought might result in thermally stable spherical retroreflectors, provided the tensile strength of the cladding class is not exceeded. Unfortunately, FEA modeling revealed that this substitution for the original $\mathrm{ZnS}$ core material reduces the peak stress only by about one half (see Figure 15), which still exceeds the damage threshold by about a factor of three.

(g) http://www.ansys.com/

(h) http://solidworks.com/ 


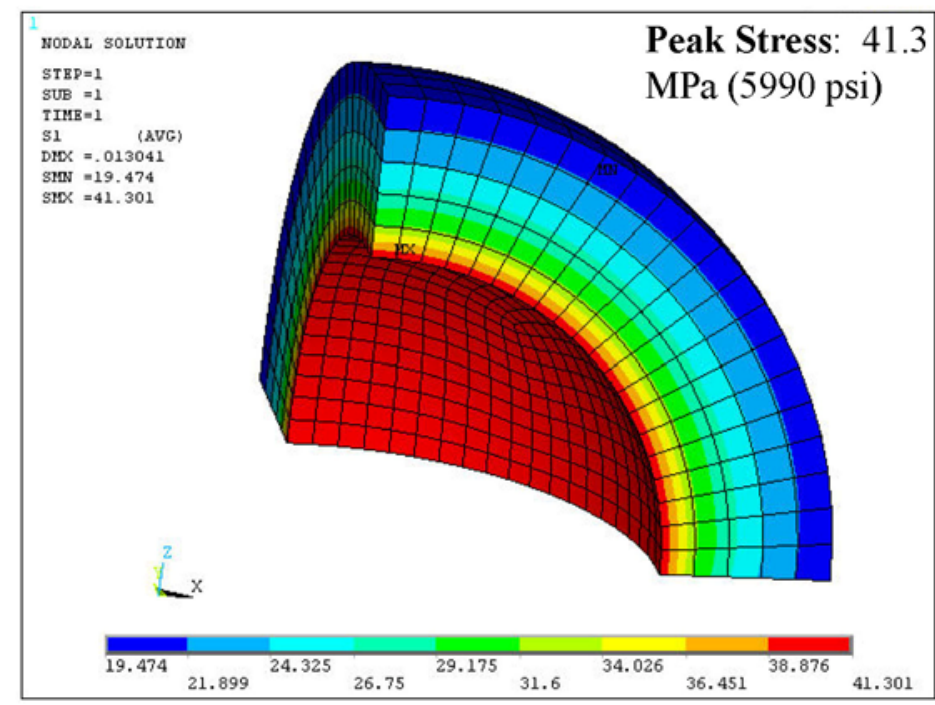

Figure 14. FEA Modeling Results Showing the Peak Stress that Develops at the Boundary Between the ZnS Core and IG3 Shell After Cooling Following a Molding Sequence in the Fabrication of the Clad Ball Miniature Retroreflectors

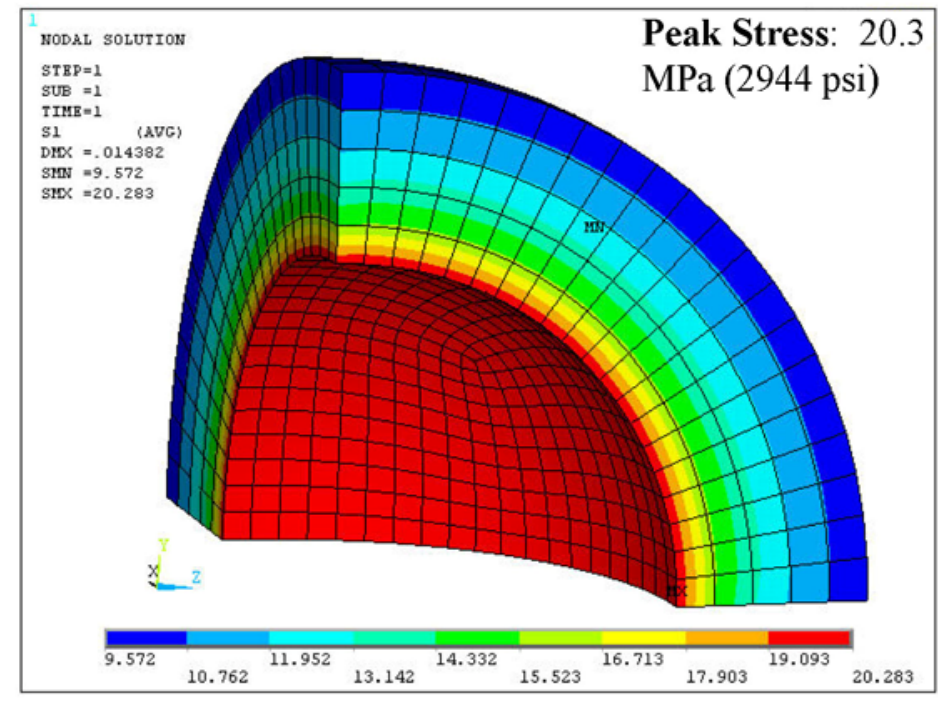

Figure 15. FEA Modeling Results for the Design in which GLS Glass is Substituted for the ZnS Core. Although the CTE for GLS is 1.5 larger than ZnS, the peak stress after cooling still exceeds the damage threshold and will result in component failure.

Finally, we used the FEA model to determine the necessary CTE required of a candidate core material so that tensile stress due to cooling would not exceed the 1-kpsi limit. Considering IG3 with a CTE of $13.4 \mathrm{ppm}$, a core material having a CTE of $12.3 \mathrm{ppm}$ is required to achieve an equilibrium stress value of 953 psi. Therefore the step-index clad design requires materials with the proper index of refraction, optical transmission, and a core $\mathrm{CTE} \leq 1.1 \mathrm{ppm}$ of the shell to provide a stable geometry. To date, no 
candidate solutions have been discovered to meet this nearly matched CTE requirement between core and cladding.

Alternatively, we also considered assembly of the compression molded glass hemispherical shells and core ball at room temperature using room-temperature-curable epoxies to bond the two shell halves at the seam line, but this was never brought into practice due to the low yields of the shell production.

\subsection{Alternative Designs}

\subsection{Spherical Half-Clad Miniature Retroreflector}

In the process of molding the clad balls, we observed that the mode of failure during cooling depends on the integrity of the bond of the seam line between the two shell halves. If the bond is weak, the mode of failure results in the two shell halves popping loose from the assembly. If the bond is strong, the increased stress shatters the shell halves. With this in mind, we undertook an analysis to determine a variant of the clad ball design in which only one shell half is required. The drawback to this design is that the resulting structure is not isotropic, but the component still retains the benefit of a large acceptance angle when compared to traditional retroreflector designs, such as the corner cube or cat's eye reflectors. A design of a half-clad retroreflector is shown in Figure 16, optimized for performance at $10 \mu \mathrm{m}$. The Strehl Ratio for the design is shown as a function of input beam diameter in Figure 17. Using this data, a cross section of $9.4 \mathrm{~m}^{2}$ is predicted at an aperture diameter of $3.85 \mathrm{~mm}$. In order to compare these results with those shown previously, the design was constrained such that the radius of curvature of the outer clad was equivalent to the fully clad design, or about $4.8 \mathrm{~mm}$. This value for the cross-section figure of merit falls between the $\mathrm{n}=2$ HMOX design of $6.9 \mathrm{~m}^{2}$ and $11.2 \mathrm{~m}^{2}$ for the fully clad design for designs having an equivalent physical aperture. Although the cross section is smaller than the fully clad design, the half-clad approach still ensures a large acceptance angle, potentially increased manufacturing yield, and furthermore offers the opportunity to reflectively coat the rear surface of the assembly and antireflection coat the first surface to obtain more efficient return when compared with the theoretical 14.8\% return efficiency described earlier in the report. The return from a reflective-coated half-clad retroreflector would have a theoretical maximum return efficiency of nearly $100 \%$. If no anti-reflection coating were applied to the entry surface, its return efficiency would fall to $60.4 \%$. 


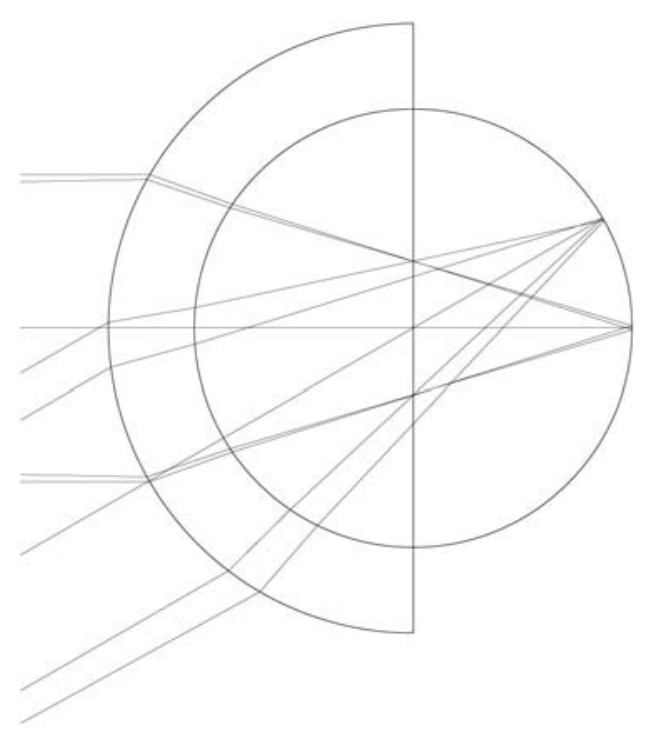

Figure 16. Half-Clad Miniature Retroreflector Utilizing a ZnSe Core and IG3 Cladding. The device still maintains a large acceptance angle in the incident half space, but ceases to be isotropic. For the design shown above, the core ball has a 5.5-mm diameter, with a cladding thickness of $1.07 \mathrm{~mm}$ or IG3 glass.

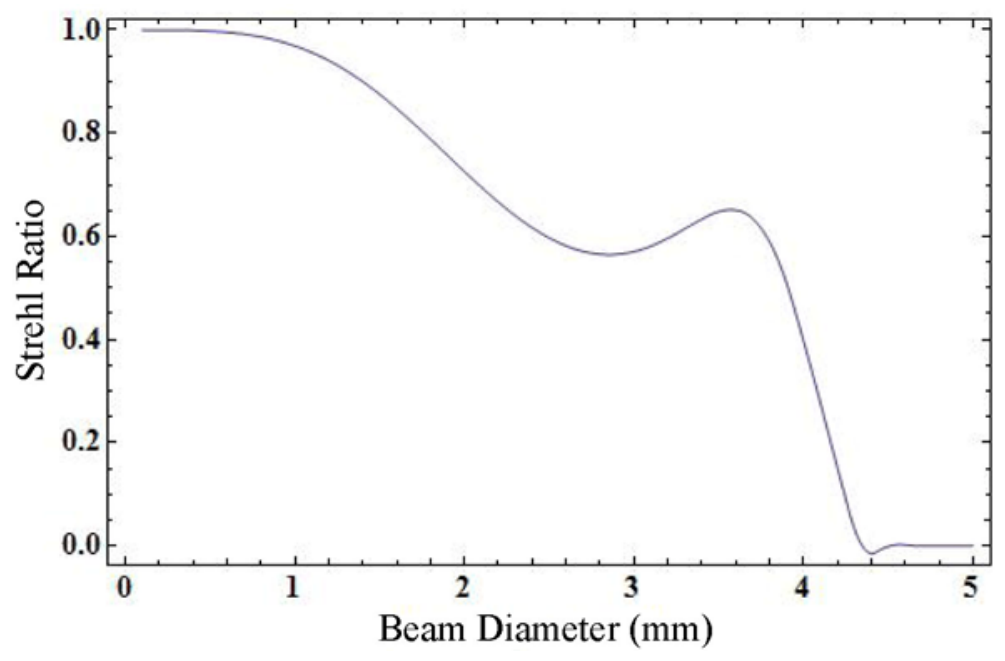

Figure 17. Strehl Ratio versus Input Beam Diameter for the Half-Clad Design. Using this data, the peak cross section of $9.4 \mathrm{~m}^{2}$ was calculated for an input beam diameter of $3.85 \mathrm{~mm}$.

\subsection{Aspherical Half-Clad Miniature Retroreflector}

A variation of the half-clad design can be realized in which the capping layer is embossed with an aspheric profile during the cladding operation. Although this results in vastly improved cross sections for an on-axis beam, performance falls off quickly as a function of field angle, making this design suitable 
only for applications in which the beam can be constrained within an angular spread of $\pm 5^{\circ}$ or so. For example, when the design in Figure 16 is aspherized, the on-axis cross section is increased to $37.23 \mathrm{~m}^{2}$, but at $\pm 15^{\circ}$, falls off to $0.73 \mathrm{~m}^{2}$. A plot showing the Strehl Ratio for these two angular fields in the aspheric half-clad variant is provided in Figure 18, which shows the dramatic fall off in Strehl Ratio with field angle for the aspherized shell. Although the on-axis improvements are impressive, its use as a wideangle retroreflector is not recommended.

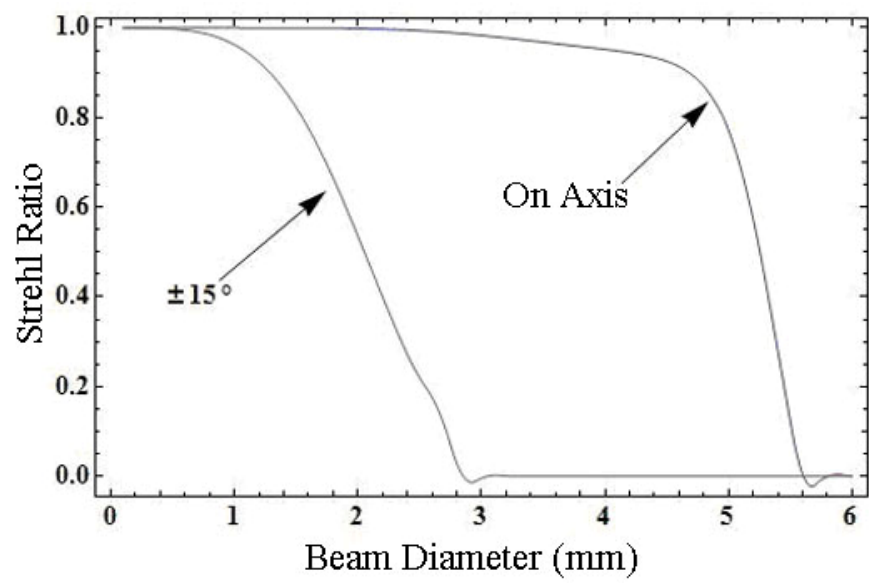

Figure 18. Strehl Ratio (and hence cross section) as a Function of Field Angle in the Case of an Aspherically Embossed Half-Clad Miniature Retroreflector

\subsection{Conclusions}

The design and fabrication process to produce miniature infrared spherical retroreflectors has been described, including comparative design and modeling results for homogeneous, gradient index, and stepindex full- and half-clad designs. The calculated CS values were used to determine the normalized standoff detection range potential for each retroreflector design. The analysis results showed that the step-index design's 33\% CS reduction (as compared to the spherical gradient-index design) led to a standoff range reduction of only $10 \%$. This is a significant result and it should serve to temper ambitions to develop spherical gradient fabrication methods if they become costly endeavors or if a $90 \%$ solution (step-index) or $80 \%$ solution (single-index HMOX glass) will satisfy the deployment requirements.

We have also described our process development progress using visible moldable glass (Super Vidron), initial molding results using infrared chalcogenide cladding glass (IG3 from Vitron GmbH), and infrared core glass materials ( $\mathrm{ZnS}$ and GLS for fully-clad, and $\mathrm{ZnSe}$ for half-clad designs). The performance of the compression molding press has enabled us to fabricate mechanical prototype retroreflectors using moldable Super Vidron glass for the cladding and BK7 glass for the core, and has resulted in significant cost reduction in lieu of using more expensive infrared glass at this early stage of development. The thermal expansion mismatch between the core and cladding materials was identified as 
a major challenge in both Super Vidron-BK7 and IG3-ZnS material systems. This is an unfortunate consequence of the clustering of physical properties of a moldable glass; namely, the low $\mathrm{T}_{\mathrm{g}}$ that permits molding at reasonable temperatures along with a correspondingly high CTE. It was thought that the IG3-GLS system could potentially reduce this effect to a greater extent, but experimental results and FEA modeling showed that tensile stresses caused during cooling still exceeded the mechanical strength of the shell material. A search for better CTE-matched core and cladding glasses has thus far proved fruitless. Alternatively, the fabrication process developed thus far can be completed by using room-temperature curable epoxies to bond the shells to the ball core at the seams. Although there will be an epoxy seam line that may distort the incoming beam slightly, the effects on retroreflector performance should be negligible. Depending on the application, the retroreflector could be aligned such that the seam line is not in the propagation path of the incident beam. A half-clad design was presented that would increase the yield of the molded retroreflector fabrication approach. The half-clad design exhibited cross-section performance falling between the homogeneous ball with index of 2 and the optimized fully clad ZnS-IG3 retroreflector, making it an optically efficient solution for many deployment scenarios.

\subsection{References}

Born M and E Wolf. 1986. Principle of Optics, 6th Ed. Pergamon Press, Oxford.

Burmistrov V, N Parkhomenko, Y Roy, V Shargorodsky, JD Vasiliev, S Habib, V Glotov and N Sokolov. 2003. "Spherical Retroreflectors with an Extremely Small Target Error: International Experiment in Space." 13th International Workshop on Laser Ranging "Toward Millimeter Accuracy", Proceedings From the Science Session and Full Proceedings CD-ROM. Washington, DC (2002). edited by Ron Noomen, Steven Klosko, Carey Noll, and Michael Pearlman, NASA/CP-2003-212248. pp. 1-6.

Doyle KB and MA Kahan. 2003. "Design Strength of Optical Glass." Proceedings of SPIE, Optomechanics 2003. August 7, 2003. San Diego, California. The International Society for Optical Engineering (SPIE), Bellingham, Washington. pp. 14-25.

Handerek V, C Boulet, M Griffith and L Laycock. 2006. "Coherent System Tests of Experimental Retroreflectors with Very Wide Field of View for Free-Space Optical Communications." 3rd EMRS DTC Conference, Session B: Electro-Optic Systems, Embedded Processing, Devices \& Materials. Electro Magnetic Remote Sensing Defence Technology Centre Technical Conference Digest.

Handerek V, H McArdle, T Willats, N Psaila and L Laycock. 2005. "Experimental Retroreflectors with Very Wide Field of View for Free-Space Optical Communication." 2nd EMRS DTC Technical Conference, Unmanned/Unattended Sensors and Sensor Networks II. October 26, 2005. Bruges, Belgium. DOI 10.1117/12.630556. The International Society for Optical Engineering. p. 598611.

Kikuchi K, T Morikawa, J Shimada and K Sakurai. 1981. "Cladded Radially Inhomogeneous Sphere Lenses." Appl. Optic 20:388-394.

Klocek P, Ed. 1991. Handbook of Infrared Optical Materials. Marcel Dekker, New York. p. 415. 
Koike Y, N Tanio, E Nihei and Y Ohtsuka. 1989. “Gradient Index Polymer Materials and Their Optical Devices.” Polymer. Eng. Sci. 29(17):1200-1204.

Maschmeyer RO, CA Andrysick, TW Geyer, HE Meissner, CJ Parker and LM Sanford. 1983.

"Precision-Molded Glass Optics." Appl. Optic 22:2410-2412.

Oakley JP. 2007. "Whole-angle spherical retroreflector using concentric layers of homogeneous optical media." Appl. Optic 46:1026-1031.

Pickering AM, RL Taylor and DT Moore. 1986. “Gradient Infrared Optical Material Prepared by Chemical Vapor Deposition.” Appl. Optic 25:3364-3372.

Welford WT. 1986. Aberrations of Optical Systems. Adam Hilger, Boston.

Zhang XH, Y Guimond and Y Bellec. 2003. "Production of Complex Chalcogenide Glass Optics by Molding for Thermal Imaging." J. Non-Cryst. Sol. 326-327:519-523.

Zürcher W, R Loser and SA Kyle. 1995. "Improved Retroreflector for Interferometric Tracking in Three Dimensions." Opt. Eng. 34:2740-2743. 


\section{Distribution}

No. of

Copies

1 Dr. Victoria T. Franques

U.S. Department of Energy

NNSA/NA-22

1000 Independence Ave. SW

Washington, DC 20585

1 Dr. Rhys M. Williams

U.S. Department of Energy

NNSA/NA-22

1000 Independence Ave. SW

Washington, DC 20585

1 Mr. Eric Sanders

U.S. Department of Energy

NNSA/NA-22

1000 Independence Ave. SW

Washington, DC 20585

1 Dr. Vaughn Standley

U.S. Department of Energy

NNSA/NA-22

1000 Independence Ave. SW

Washington, DC 20585
No. of

Copies

10 Internal Distribution

Pacific Northwest National Laboratory

P.O. Box 999

Richland, WA 99352

Anheier, NC

K5-25

Bernacki, BE

K5-25

Bruckner-Lea, C

K5-25

Klymyshyn, NA

K5-25

Rodriguez, CP

K6-24

Sharpe, SW

K8-88

Information Release (2)

K1-06 


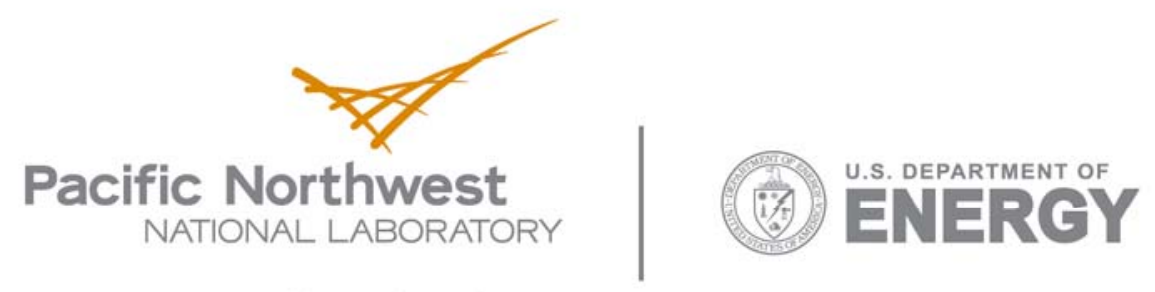

902 Battelle Boulevard

P.O. Box 999

Richland, WA 99352

1-888-375-PNNL (7665)

www.pnl.gov 